\title{
Crise dentro da crise: a pandemia da violência de gênero
}

Renata Barreto Malta (https://orcid.org/0000-0002-7414-9081), Departamento de Comunicação Social da Universidade Federal do Sergipe (UFS), São Cristóvão, Sergipe, Brasil'.

Tatiana Güenaga Aneas (https://orcid.org/0000-0002-5681-6215), Departamento de Comunicação Social da Universidade Federal do Sergipe (UFS), São Cristóvão, Sergipe, Brasil".

Aline Lisboa (https://orcid.org/0000-0003-3850-5461), Universidade Estadual Paulista "Júlio de Mesquita Filho" (Unesp), Bauru, São Paulo, Brasil"'.

Iasmim de Araujo Vieira (https://orcid.org/0000-0001-9772-9516), Universidade Estadual de Campinas (Unicamp), Campinas, São Paulo, Brasil'v.

Resumo: Este artigo se propõe a analisar como textos informativos publicados em sites brasileiros apresentam a violência de gênero no contexto da pandemia de Covid-19, partindo do pressuposto de que o isolamento social e suas consequências políticas e econômicas ampliam o processo de ameaça aos direitos das mulheres. Como método, optamos pela análise de conteúdo do corpus e a discussão dos resultados, embasadas em estudos de gênero e na teoria feminista. Os principais resultados apontam para a predominância de conteúdos jornalísticos e com diferentes linhas discursivas, mesmo que a violência doméstica seja central. A ausência de fontes advindas dos movimentos de mulheres e de uma discussão centrada nas causas da violência de gênero que questione a estrutura familiar e o lar como ambiente seguro para mulheres em confinamento é sintomática do atual cenário de retrocesso, ainda que a pandemia tenha dado visibilidade ao problema.

Palavras-chave: Covid-19. Isolamento social. Violência de gênero. Textos informativos. Análise de conteúdo.

\section{Crisis inside the crisis: the pandemic of gender violence}

Abstract: This article aims to analyze how informational texts by Brazilian journalistic and institutional sources present gender violence in the context of Covid-19 pandemic, basing on the premise that social isolation and its political and economic consequences enlarge the threat to human rights. As a method, we have opted for content analysis of the corpus and the discussion of the results is based on gender studies and feminist theory. The main results point to the predomi-
I. Renata Barreto Malta é professora efetiva do

Departamento de Comunicação Social da UFS, professora permanente do Programa de Pós-Graduação stricto sensu em Comunicação Social (PPGCOM) da UFS. <renatamaltarm@ gmail.com>

II. Tatiana Guenaga Aneas é professora efetiva do Departamento de Comunicação Social e membro permanente do Programa de Pós-graduação em Comunicação (PPGCOM) da Universidade Federal de Sergipe. <tatiana.aneas@ gmail.com>.

III. Aline Lisboa é professora dos cursos de comunicação da Unesp, bolsista Capes do doutorado pelo Programa de Mídia e Tecnologia da Unesp. <alinelisboa.silva@ gmail.com>.

IV. Iasmim de Araujo Vieira é doutoranda em sociologia pela Unicamp. <iasmimva@gmail. com>. 
nance of journalistic content, with different discursive lines, although domestic violence is central. The absence of sources from women movements, as well as the debate centered on the causes of gender violence which questions the family structure and home as a safe place to confined women is symptomatic of the current scenario of setback, although the pandemic has provided visibility to the problem.

Keywords: Covid-19. Social isolation. Gender violence. Informational texts. Content analysis.

\section{Introdução}

- ste estudo considera como base a sociedade brasileira que, embora tenha sido cenário de diversas conquistas por parte das mulheres ao longo de sua história no que concerne a direitos civis e políticos, permanece alicerçada em uma ordem patriarcal de gênero (Saffioti, 2015). Se, por um lado, o fortalecimento do movimento feminista no país consolida um embate mais visível e sua voz se fez ecoar em debates pulverizados nas mais variadas esferas sociais, em ambientes presenciais e virtuais, por outro, uma recente mudança de rumo da política brasileira fez crescer discursos machistas e misóginos que, minimamente, representam um retrocesso social. A dimensão desse retrocesso ainda é latente e "é bastante provável que só a história venha nos permitir saber o tamanho e a intensidade da devastação que as forças de direita estão promovendo no país" (Rodrigues, 2016: 30). Uma direita, acrescente-se, posicionada na extrema ponta do espectro ideológico, caracterizada pelo conservadorismo, pelo militarismo, pelo negacionismo e pelo fundamentalismo religioso, e que esvazia o Estado de políticas públicas voltadas para minorias e grupos desfavorecidos.

Trata-se de um grupo político que ascende ao poder legitimado (e desejado) pela inépcia em reconhecer o direito de existência do outro. Nesse sentido, Francisco Ortega e Michael Orsini (2020:1258, tradução livre) sugerem que "a marca do governo de Bolsonaro representa um mergulho no que alguns acadêmicos se referem como 'a corrupção da democracia'”, escancarando as desigualdades sociais. Um modelo que afiança a continuidade do patriarcado e sua face mais cruel de dominação/exploração, notadamente marcado pelo controle e o medo (Saffioti, 2015). A violência contra a mulher resulta dessas relações desiguais, em decorrência de sua condição historicamente produzida em um lugar de subordinação e inferioridade. Complexifica-se ainda mais essa condição quando analisadas as suas intersecções com classe e raça/etnia, por exemplo. Ainda que cada pilar da dominação/exploração - gênero, raça/etnia e classe - resguarde uma lógica própria de funcionamento, eles não atuam separadamente, ao contrário, adquirem uma dinâmica especial quando entrelaçados em um nó que é frouxo e que permite "mobilidade para cada um de seus componentes" (Saffioti, 2015: 133). 
É preciso reconhecer, aqui, as variadas formas de violação que ferem a autonomia, a autoestima e a integridade física e psicológica da mulher, além de outras facetas que são produzidas nas desiguais relações de gênero - considerando suas intersecções - e que escancaram a sobrecarga de trabalho - incluindo o doméstico -, as diferenças salariais, a falta de leis que garantam o direito ao próprio corpo, entre outras. Todas essas questões, ainda que velhas conhecidas, foram trazidas para o debate quando associadas à atual condição de isolamento social recomendada pela Organização Mundial da Saúde (OMS) como forma mais eficaz de diminuir o contágio do novo Coronavírus, no Brasil especialmente a partir de março de 2020. A necessidade de confinamento traz à tona a reflexão sobre o espaço do lar como lugar inseguro para uma parcela significativa de mulheres e, de forma mais profunda, o ambiente doméstico como símbolo do poder patriarcal.

Sobre o espaço da casa e da família, a partir de uma leitura crítica de Habermas, Nancy Fraser (1989) chama atenção para as limitações de uma classificação dicotômica entre esfera pública - entendida como o espaço de ação estratégica e da reprodução material - e esfera privada - que seria, na definição habermasiana, lugar de ação consensual e da reprodução simbólica. Segundo a autora, uma divisão em "diferenças absolutas" é problemática, posto que a família pode também ser

\footnotetext{
lugar de cálculos egocêntricos, estratégicos e instrumentais, de intercâmbios exploratórios de serviços, trabalho, dinheiro e sexo - e frequentemente, lugar de coerção e violência (Fraser, 1989: 120, tradução livre).
}

O contraste que não considere influências entre a família e o sistema formado por Estado e economia capitalistas tende a ocultar essas relações, e a entender a noção de poder como pertinente exclusivamente a contextos burocráticos.

Há um superdimensionamento das diferenças entre as instituições que bloqueia a possibilidade de analisar as famílias como sistemas econômicos, isso é, como lugar de labor, troca, cálculo, distribuição e exploração (Fraser, 1989: 121, tradução livre).

A relevância dessas observações nos permite ampliar o debate e compreender que o sistema de desigualdades entre homens e mulheres se estrutura também nessas divisões dicotômicas. O slogan "o pessoal é político", amplamente difundido no Brasil pela teoria e pelo movimento feminista a partir de 1970, sintetiza a crítica feita ao conteúdo patriarcal que embasa o discurso neoliberal e que, por sua vez, fortalece e impõe tal separação. O que se evoca no argumento feminista é a existência de uma conexão estrategicamente invisibilizada entre as duas esferas da vida, que 
determina os espaços de atuação dos homens e das mulheres e que resguarda o poder masculino às duas. Resulta, em um primeiro momento, o entendimento de que a vida doméstica é estruturada por fatores da esfera pública e, desta forma, resolvidos também por meios políticos (Pateman, 1996).

Ao partir dessa problemática, o presente artigo tem como objetivo analisar os conteúdos textuais sobre o machismo e, mais especificamente, a violência contra a mulher, no contexto de isolamento social provocado pela Covid-19 em sites informativos brasileiros no primeiro momento da pandemia. Para tanto, propomos uma pesquisa empírica a partir da análise de conteúdo de um corpus criteriosamente selecionado - cujo método será posteriormente explicitado - que possibilite responder quais foram os aspectos de relevância dos textos que circularam na internet, provenientes de fontes jornalísticas e institucionais brasileiras, durante o primeiro mês de quarentena consequente da pandemia do novo Coronavírus, focados em uma questão específica, a desigualdade de gênero. Alicerçadas nos resultados das análises, realizaremos uma discussão teoricamente fundamentada com a finalidade de compreender o fenômeno social apresentado, senão em sua totalidade, ao menos no recorte temporal e espacial exposto, proporcionando a emersão de um debate social urgente.

\section{O estado da arte:}

\section{Covid-19 e violência de gênero}

No que concerne ao estado da arte, por meio de uma bibliometria nas principais bases acadêmicas e com palavras-chave em português, identificamos uma dezena de artigos científicos sobre o tema, publicados em revistas dos campos da saúde, antropologia social, filosofia, psicologia, educação, além de periódicos multidisciplinares.

Na maior parte dos casos, as publicações se centraram na discussão do fenômeno com base em pesquisa bibliográfica e documental. A realização de entrevistas com assistentes sociais e psicólogas também foi um método identificado (Tchalekian \& Paiva, 2020). Dentre os documentos analisados, conteúdo jornalístico e governamental foi o mais frequente e, neste sentido, observamos uma aproximação com a proposta do presente artigo (Maranhão, 2020; Pisani, 2020; Insfran \& Muniz, 2020). No entanto, em nenhum desses estudos a coleta de um corpus amplo, representativo e não aleatório se fez presente. De fato, o material jornalístico e governamental foi acionado deliberadamente para exemplificar a problemática discutida, em um movimento metodológico oposto ao que propomos. 
Quanto ao teor das discussões, observamos uma maioria de artigos centrados na violência doméstica e, mais especificamente, no feminicídio durante o isolamento social provocado pela Covid-19. O cruzamento entre dados oficiais concernentes ao aumento de casos de agressão e feminicídio durante a quarentena e de outros materiais de análise foi central e direcionou os artigos a diferentes enfoques. A universalização da violência de gênero refletida a partir da pandemia como fenômeno global conduziu algumas das produções a relativizar marcadores sociais relacionados a gênero, como classe e raça/etnia. Os resultados dessas pesquisas indicam que o isolamento social por imposição política e epidemiológica é o ambiente propício para a ocorrência de atos de violência e mortes de mulheres, com notícias de feminicídio em países de realidades sociais díspares (Maranhão, 2020; Pisani, 2020).

Com olhar voltado às especificidades que complexificam as relações de gênero no contexto da pandemia e baseados em dados que evidenciam as vulnerabilidades de determinados grupos sociais - como os de mulheres pobres e negras -, alguns estudos fazem uma forte crítica à debilidade de políticas públicas no Brasil para o enfrentamento da violência de gênero (Pessoa \& Nascimento, 2020; Tchalekian \& Paiva, 2020), As autoras referenciam esse modelo de gestão como necropolítica termo cunhado por Achille Mbembe (2018) -, com a total negligência do Estado e a responsabilização da própria sociedade.

Na busca por contextualizar o conhecimento produzido sobre o tema, deparamo-nos com um único artigo que buscou enaltecer e analisar iniciativas espontâneas de criação de rede de apoio para mulheres durante o isolamento social, como grupos de acolhimento nas redes sociais, rodas de mães e experiência de escuta psicológica. O estudo conclui que

somente o caminho coletivo, onde a sororidade se faz presente como forma de cuidado e resistência, pode levar à superação das desigualdades, intensificadas neste contexto pandêmico (Insfran \& Muniz, 2020: 26).

Com o intuito de realizar uma revisão sistemática de literatura, a partir de artigos e ensaios científicos sobre os impactos do isolamento social no aumento da violência doméstica contra a mulher, Solange Monteiro e equipe (2020) concluíram que, ainda no primeiro trimestre da quarentena, os estudos coletados apenas visibilizaram questões preexistentes, como o aumento da violência contra a mulher e os efeitos da desigualdade social e de direitos entre os gêneros. Constataram também que as mulheres estão mais sobrecarregadas com os cuidados domésticos, dos filhos e da comunidade, estando também presente na maioria das linhas de frente no sistema 
de saúde. Desse modo, a produção científica analisada escancara um velho problema de cunho social, que mostra a sua face mais cruel com o isolamento social.

Finalizamos este tópico evidenciando que, apesar do conteúdo jornalístico e de fontes governamentais que circularam na internet durante a pandemia estarem presentes nos estudos identificados para a contextualização do estado da arte, não identificamos pesquisas que se debruçaram a entender esses discursos de forma mais ampla e sistemática, como nos propomos como caminho metodológico.

\section{Trajetória empírica:}

\section{o método em foco}

Primeiramente, faz-se relevante contextualizar que o presente artigo é parte de um projeto de pesquisa intitulado "Isolamento social e machismo: um debate urgente em tempos de pandemia", o qual se propôs a investigar os conteúdos midiáticos que circularam na internet concernentes ao tema. O projeto contou com duas etapas de análise, uma centrada em postagens do Twitter - selecionadas a partir dos mesmos termos e coletadas igualmente na fase inicial de isolamento social no Brasil -, cujos resultados foram publicados em um dossiê temático da Revista Comunicação \& Inovação (autoria omitida para revisão às cegas, 2020). Nessa etapa, optamos pela análise de redes semânticas e processamento do corpus com uso de software, considerando a extensão do mesmo. A segunda fase analítica deu forma a este artigo.

Para a coleta do corpus, foram realizadas leituras flutuantes a partir de buscas aleatórias por meio da ferramenta do Google tendo como base a combinação das seguintes palavras-chave (as mesmas elencadas para a coleta das postagens do Twitter anteriormente mencionada):

$$
\begin{aligned}
& \text { i. Coronavírus + machismo; } \\
& \text { ii. Covid-19 + machismo; } \\
& \text { iii. Coronavírus + violência + mulher; e } \\
& \text { iv. Covid-19 + violência + mulher. }
\end{aligned}
$$

A escolha das palavras-chave foi a mesma para todo o estudo, por entendê-las como termos representativos de dois universos que se confluem para abarcar o fenômeno investigado. No que concerne à combinação $i$ e ii, foram salvos todos os materiais recuperados, e excluídos aqueles que não se referiam ao período da pan- 
demia. No que tange às combinações iii e iv, como o resultado da busca foi muito superior quantitativamente, procuramos equiparar a quantidade de materiais coletados à das combinações $i$ e ii. Em todo caso, exploramos de forma não sistemática os resultados posteriores aos coletados, e não encontramos quantidade significativa de publicações pertinentes para esta pesquisa. Após a etapa de filtragem, selecionamos o total de 106 conteúdos de diferentes fontes datados entre 14 de março de 2020 e 13 de abril de 2020 (quando a seleção ocorreu).

Cabe ainda ressalvar que os critérios de "relevância" acionados pelos algoritmos da ferramenta de busca devem ser tratados de forma cautelosa, já que além de serem atualizados constantemente (o que não permite que os resultados da pesquisa sejam replicados), esbarram em referenciais próprios da Google Inc. e estão sujeitos a variáveis relativas a uma série de aspectos como a localização geográfica do pesquisador, indicações e previsões das mais variadas (Valente, 2020). Ao considerar essas ressalvas, e evidenciado que procedimentos básicos foram realizados quando acionamos o modo anônimo do navegador para a busca, entendemos que prevalece a aleatoriedade e que o corpus resultante tem potencial para garantir uma pesquisa de qualidade acadêmica.

Como método, optamos pela análise de conteúdo quantitativa, com discussão qualitativa dos resultados, com foco na frequência com que surgem determinadas características do conteúdo e em elementos variáveis (como temáticas) previamente codificadas. Para a sua aplicação, Laurence Bardin (2009) sugere a divisão em etapas: pré-análise (definição do corpus); exploração do material; tratamento dos resultados; inferência e interpretação. No processo de exploração do material, definimos as seguintes unidades de análises:

i. data de publicação do conteúdo;

ii. tipo de fonte (jornalística, governamental, sindical, entre outras);

iii. posicionamento ideológico da fonte; e

iv. títulos e subtítulos do conteúdo selecionado.

Uma vez identificadas e codificadas as unidades de análise, foi possível partir para a categorização. Evidenciamos que diferentemente da etapa anterior do estudo, aqui não se fez necessário o uso de software para processamento dos dados, tendo em vista a viabilidade de análise manual e necessidade de cruzamento de informações. Sobre a delimitação dos títulos e subtítulos de todas as páginas selecionadas no processo de coleta, consideramos tratar-se do elemento de destacabilidade e, po- 
tencialmente, resumir os pontos principais abordados no texto. Após sua categorização, organizamos os resultados em palavras-chave. O processamento de todas as palavras-chave resultantes dessa fase da pesquisa possibilitou a sistematização do conteúdo em tópicos. Na sequência, apresentaremos os principais resultados empíricos do estudo, já com a discussão e o embasamento teórico que emergem dos dados.

\section{Entre dados e discussões: elementos pré-discursivos}

Antes de partir propriamente para a análise do conteúdo, identificamos a origem da fonte (Gráfico 1) e um possível posicionamento ideológico explícito (Gráfico 2).

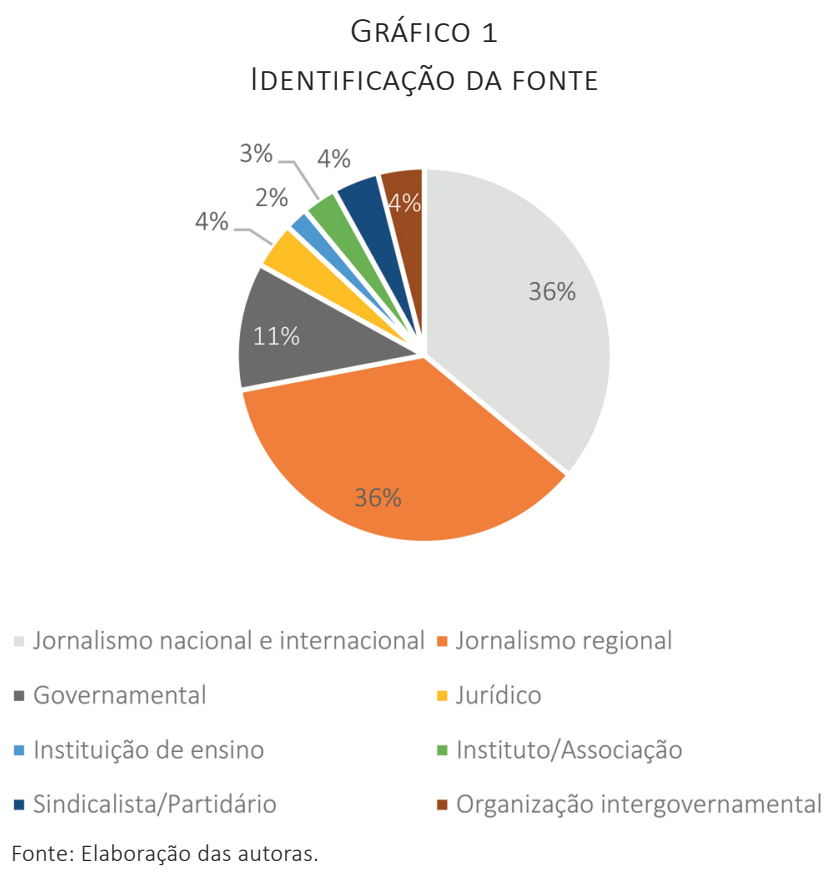

No que concerne à identificação da fonte, observamos a prevalência de conteúdo jornalístico, tanto na esfera nacional e internacional (representado por portais de notícias tradicionais, como Terra, Uol, R7 e Globo.com, mas também por mídias alternativas, como Catraca Livre e Esquerda Diário), quanto na esfera estadual e regional (com uma grande variedade de regiões). Sobre esse aspecto, ao sistematizar as palavras-chave em categorias, identificamos 34 ocorrências relacionadas a cidades, estados e países. Os dados acerca de municípios e estados revelam a importância do jornalismo regional para o debate social, ao considerarmos a rele- 
vância da problemática em questão. Como afirma Sônia Aguiar (2016), os meios locais e regionais devem ser interpretados como "subsistemas" do sistema midiático abrangente, com especificidades próprias, e não como "inferiores" em comparação à "mídia nacional".

Outra reflexão a partir dos resultados mencionados diz respeito à universalização da violência contra a mulher. Ainda que essa concepção não seja capaz de abarcar as diferenças e compensar brechas e omissões marcadas em classe, raça/etnia, sexualidade e nacionalidade no interior do próprio feminismo e, assim, numa relação "intragênero" (Ballestrin, 2017), e que a geopolitização do debate feminista seja prerrogativa fundamental, também é certo que a condição de gênero é determinante nas relações de poder e estrutura as mais distintas sociedades. Sobre as tensões e afrouxamentos que essa discussão provoca, Virginia Vargas Valente (2005) apresenta um amplo e heterogêneo movimento popular de mulheres que passou a expressar as diferentes formas de entender e atuar sobre sua situação de subordinação e exclusão social. Embora as diversas vertentes que se fizeram presentes - com atenção aqui para a América Latina - tenham desenvolvido seus próprios objetivos, dinâmicas e modos de confrontar o patriarcado, perfilando variados interesses - por vezes contraditórios -, elas também identificam muitos pontos de intersecção. Certamente os resultados aqui apresentados descortinam uma dessas confluências, a violência contra as mulheres de diferentes regiões brasileiras e países do mundo que se acentua - ou se revela com maior evidência - em tempos de isolamento social, entendida como questão de saúde pública e de violação dos direitos humanos pela OMS. Um problema de tamanha gravidade que atinge quase um terço das mulheres do globo (Maranhão, 2020).

Quanto às outras fontes identificadas, como mostra o Gráfico 2, a terceira mais frequente foi a governamental, nas esferas municipal, estadual e federal e de distintas pastas e secretarias. As demais fontes não apresentaram resultados expressivos em comparação ao universo total, no entanto, exibem importância para o estudo por potencialmente trazerem perspectivas ideológicas específicas, como é o caso das sindicalistas e de algumas associações.

Ao centrarmos nossas atenções no posicionamento ideológico da fonte, percebemos que a maior parte do corpus pressupõe neutralidade, ao menos explícita. Essa preponderância de uma posição política evidenciada como neutra pode ser explicada através do valor atribuído pelo jornalismo e pelos/as jornalistas a critérios como objetividade e imparcialidade. Ao realizar ampla pesquisa bibliográfica, Antonio Hohlfeldt (2004) constata um processo de questionamento e relativização da validade epistemológica da noção de objetividade nos estudos do jornalismo, ao 


\section{GRÁFICO 2 \\ POSICIONAMENTO IDEOLÓGICO DA FONTE}

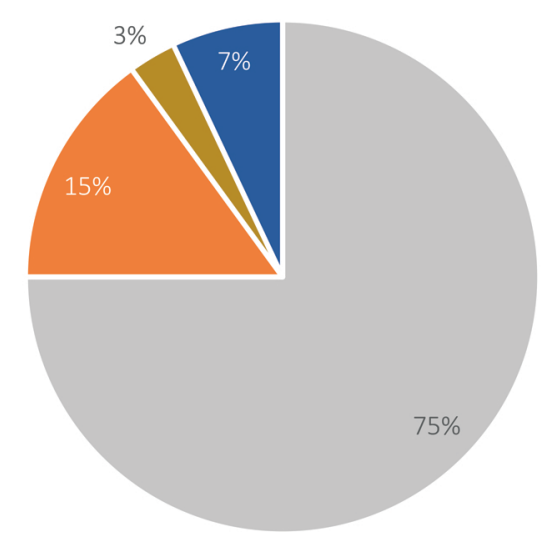

- Não explícita - Explícita de esquerda - Explícita de direita/conservadora - Feminista

Fonte: Elaboração das autoras.

passo em que reconhece que se trata de um critério "ainda mistificado por vários segmentos, tanto profissionais como da opinião pública" (Hohlfeldt, 2004: 39).

Quando a direção política foi evidenciada, a maioria apresentou-se como de esquerda, seguida da feminista. Em poucos casos observamos fontes que se autodeclararam conservadoras ou de direita. Sobre isso, lembramos, com Norberto Bobbio (1995), que a classificação em esquerda ou direita não deve ser tomada como pura expressão do pensamento ideológico, posto que não são apenas critérios descritivos. Indicam, antes,

programas contrapostos com relação a diversos problemas cuja solução pertence habitualmente à ação política, contrastes não só de ideias, mas também de interesses e de valorações a respeito da direção a ser seguida pela sociedade (Bobbio, 1995: 33).

Reconhecidas as contingências históricas que tendem a relativizar os conceitos de direita e esquerda, o autor realiza um esforço de contornar aspectos que possam definir os espectros políticos. Neste movimento, identifica uma diversidade de posturas diante do ideal de igualdade e associa os movimentos reconhecidos como de esquerda com a doutrina do igualitarismo, "não como utopia de uma sociedade em que todos são iguais, mas como tendência [...] a favorecer políticas que objetivam tornar mais iguais os desiguais" (Bobbio, 1995: 110). O que, por sua vez, justifica a aproximação do feminismo com a esquerda, ao partir da convicção 
de que a maior parte das desigualdades é de origem social e não natural e, enquanto tal, elimináveis.

\section{Entre dados e discussões: o conteúdo em foco}

Na etapa mais significativa da pesquisa empírica, codificamos o conteúdo de títulos e subtítulos em categorias definidas a partir dos assuntos tratados no corpus. Nesse processo, observamos que em todas as combinações de palavras-chave utilizadas para a busca prevaleceu a "violência doméstica" como tema central e que mais de $20 \%$ do corpus não apresentou qualquer outra informação para além do aumento do índice de violência doméstica. Essa preocupação encontra justificativa, pois como afirma Heleieth Saffioti (2015), a manifestação da violência contra a mulher ocorre, com muita frequência, em espaços privados, dificultando sua identificação e erradicação. No entanto, apenas sua constatação pouco contribui para a reflexão acerca de suas causas, formas de violência e possíveis ações de combate.

Sobre o restante do corpus, apresentamos, no Quadro 1, a frequência de aparição dos assuntos identificados; ressaltamos que mais de um tema pode estar presente em um mesmo texto analisado, assim, a soma ultrapassa os $100 \%$.

QUADRO 1

ASSUNTOS TRATADOS NO CORPUS

E SUA FREQUÊNCIA DE APARIÇÃO

\begin{tabular}{|l|c|}
\hline Apresentam uma entidade ou personalidade que assegura a informação & $42,9 \%$ \\
\hline Apresentam ações para combater a violência ou a desigualdade de gênero & $40,5 \%$ \\
\hline Informam como denunciar ou se proteger da violência doméstica & $19,0 \%$ \\
\hline Discutem outras relações de gênero e a pandemia & $14,3 \%$ \\
\hline Mencionam a violência contra outros vulneráveis associada à violência contra a mulher & $14,3 \%$ \\
\hline Apresentam alguma crítica a políticos ou ao Estado & $9,5 \%$ \\
\hline Discutem o machismo como causa da violência conta a mulher & $8,3 \%$ \\
\hline Tratam dos vários tipos de violência de gênero & $7,1 \%$ \\
\hline Mencionam movimentos feministas ou ONGs de defesa das mulheres & $5,9 \%$ \\
\hline Relatam casos pontuais de agressão ou feminicídio & $3,5 \%$ \\
\hline Apresentam causas questionáveis para o aumento da violência doméstica, como o desemprego & $4,5 \%$ \\
\hline Incluem marcadores sociais, como classe e raça/etnia, para a discussão de gênero & $2,4 \%$ \\
\hline
\end{tabular}

Fonte: Elaboração das autoras. 
Para a discussão sobre os achados apresentados no quadro, buscaremos cruzar dados e trazer exemplos do corpus como ilustração. Para uma melhor organização do tópico, dividiremos o texto em subtemas.

\section{Personalidades que afiançam a informação}

Chama-nos atenção o fato de que mais de $40 \%$ do conteúdo apresente uma entidade ou personalidade que afiance as informações, com 71 ocorrências em palavras-chave, e que apenas 5,9\% façam menção a movimentos feministas ou organizações não governamentais de defesa à mulher. Essa constatação revela que essas últimas instituições, embora especialistas em desigualdade de gênero e violência contra a mulher, são pouco ouvidas pela imprensa e por órgãos governamentais (fontes de maior aparição no corpus geral). Para ilustrar, depois da OMS e a figura de seu secretário-geral, o papa Francisco foi a personalidade que mais apareceu, enfatizando a preocupação do pontífice com o risco que correm mulheres em todo o mundo ao estarem confinadas com seus agressores. Parece-nos sintomático que um homem, e maior representante da Igreja católica, cujas bases se estruturam em relações de poder desiguais e na dominação masculina, seja uma das figuras mais citadas, ainda que muitas vezes seu posicionamento apoie pautas progressistas.

Nesse sentido, estudos apontam que espaços de militância antipatriarcais e jornais feministas na rede têm funcionado como ambientes que dão protagonismo aos diferentes grupos de mulheres, ampliando o debate e garantindo que essas lacunas historicamente estruturais no jornalismo tradicional se tornem menores (Rocha \& Silva, 2016).

\section{Ações de combate contra a violência}

Os distintos tipos de "violência de gênero" - termo pouco frequente no corpus foram verbalizados em pouco mais de $7 \%$ da segunda parte do material analisado. Nestes casos, além da violência física, explicitam-se a psicológica, a patrimonial, a

1. A Lei 11.340, mais conhecida como Lei Maria da Penha, cria mecanismos para coibir a violência doméstica e familiar contra a mulher. Todos os tipos de violência de gênero se enquadram nos moldes dessa lei, que foi instituída no Brasil em 2006. moral e a verbal, sempre em associação com o isolamento social. Cada uma dessas violações estão previstas nas leis brasileiras ${ }^{1}$, e dar visibilidade a elas é uma forma de desnaturalizar suas manifestações. Segundo Lourdes Bandeira (2014: 451), referindo-se às classificações da violência de gênero, "os diversos significados dessas categorias adquirem desdobramentos e implicações teóricas e práticas em função das condições e situações específicas de sua concretude".

Uma parte significativa - pouco mais de $40 \%$ - se concentrou em apresentar ações de combate à violência de gênero, sendo sua quase totalidade centrada na vio- 
lência doméstica. Dentre as ações mais frequentes, estão a aplicação de medidas protetivas e sua renovação automática, canais de denúncia por aplicativo e realização de boletins de ocorrência on-line. Apesar de se tratar de importantes canais de denúncia, é pertinente ressaltar que nem todas as mulheres têm acesso à internet e à telefonia. Ademais, neste período de isolamento social, houve restrição de atendimento em setores de assistência social, segurança pública e saúde, limitando a rede de apoio às vítimas. Para Brenna Pessoa e Elaine Nascimento (2020), não houve prioridade em se buscar soluções por parte do poder público, e os canais on-line, além de não universalistas, não se mostraram suficientemente efetivos. Mais além, para as autoras, a tática do Estado brasileiro de combater o índice de feminicídio por vias civis não mostra resultados - somos o quinto país do mundo que mais mata mulheres - e é uma forma de "atribuir boa parte da responsabilidade à sociedade civil, minimizando a do poder público" (Pessoa \& Nascimento, 2020: 38).

Em parte dos títulos e subtítulos não se explicita quais ações serão apresentadas no texto, mas a ocorrência de palavras como "medidas" e "propostas", associadas a "combate", e "proteção" indica que o conteúdo trata dessas questões. Especificamente sobre denúncias, pouco menos de $20 \%$ evidencia a importância de se denunciar e informa sobre o Disque-denúncia 180 , sendo que pouco mais de $3 \%$ noticiaram casos de agressão contra mulheres e feminicídio associados à quarentena.

\section{Para além da violência de gênero}

Afora a violência, a desigualdade nas relações de gênero potencializada pela pandemia foi assunto de quase $15 \%$ da segunda parte do corpus. A abrangência dessas desigualdades na vida cotidiana de mulheres e, consequentemente, na esfera política, é ampla, abarcando sua trajetória restrita no mundo público, as duplas ou até mesmo triplas jornadas de trabalho, os salários desiguais para as mesmas funções desempenhadas por homens, a divisão desequilibrada de responsabilidades domésticas e com o cuidado dos filhos no mundo privado, a sua tutela jurídica, o controle de suas sexualidades, entre outras (Martinez et al., 2016).

Acerca do conteúdo identificado nas análises, os holofotes se direcionam para duas problemáticas específicas: a sobrecarga de trabalho doméstico e a maioria de muIheres profissionais da saúde que estão na linha de frente para o combate ao vírus. Ainda que envolvam desigualdades diferentes, são faces de uma mesma moeda. Recorremos aqui ao estudo de Anna Bárbara Araújo (2018) sobre gênero e reciprocidade, além dos conceitos propostos por Helena Hirata e Danièle Kergoat (2007) no que concerne às esferas produtiva e reprodutiva que estruturam a divisão sexual do trabalho. 
Segundo essas autoras, uma enorme massa de trabalho era - e ainda é - realizada gratuitamente pelas mulheres em prol da sociedade. Assim, historicamente, o trabalho reprodutivo (que assegura a continuidade da espécie e da vida), invisível e não remunerado, é aculturado como função das mulheres. Neste jogo desigual atua o ideal de reciprocidade e solidariedade que "opera como mecanismo mantenedor de subordinações" (Araújo, 2018: 3), em nome da "natureza" e do "dever materno" que ora posiciona mulheres como as principais responsáveis pelo cuidado da casa e dos filhos, ora as impulsiona a "escolher" profissões centradas no cuidado do outro.

Outra leitura apropriada para o debate problematiza, mais uma vez, a ordem patriarcal que tende a separar e valorar os trabalhos socialmente determinados para homens e mulheres. Dentro da mesma distinção hierárquica entre mundo público para os homens e mundo privado para as mulheres, camufla-se a verdadeira dependência que o "trabalho de mercado" tem, por exemplo, do trabalho doméstico e de cuidado (Carrasco, 2003).

Essas teorias se materializam em números. Dados da Pesquisa Nacional por Amostra de Domicílio (Pnad 2020 - IBGE, 2020) revelam que a média de horas semanais dedicadas aos afazeres domésticos e/ou cuidado de pessoas por homens varia entre 10,4 (homens ocupados) e 12,1 (homens desocupados) e, entre as mulheres, varia entre 18,5 (mulheres ocupadas) e 54,0 (mulheres desocupadas). Ademais, segundo o Conselho Federal de Enfermagem (Cofen, 2020), 85\% dos postos do setor são ocupados por mulheres, profissionais da saúde mais expostos ao contágio do vírus. Ainda que o corpus não tenha explicitado, a sobrecarga de trabalho da esfera do cuidado que recai sobre as mulheres é um problema social que demanda atenção do Estado. "A ausência (ou a diminuição) de políticas públicas sempre foi um obstáculo a mais na vida de milhões de mulheres" (Insfran \& Muniz, 2020), o que se agrava com a pandemia.

\section{O machismo como causa}

As desigualdades nas relações de gênero que se expressam em todo o conteúdo analisado se estruturam no machismo e, por partirmos dessa premissa, optamos por utilizar o termo como palavra-chave para a seleção do corpus do estudo. Ainda assim, um número bastante inexpressivo se materializou, já que pouco mais de $8 \%$ trouxeram o machismo como assunto central. Esse fato fica ainda mais notável quando observamos que a menção a vulneráveis como crianças e idosos é mais frequente, com mais de $14 \%$ das ocorrências, equiparando a violência contra a mulher a de outros "vulneráveis" e, assim, desconsiderando o machismo como fundamento. 
Omitir o machismo como causa e apresentar atenuantes para a violência - como a utilização do termo "crime passional" ao invés de feminicídio - é historicamente uma estratégia que corrobora para a manutenção do sistema patriarcal. De fato, essa classificação tradicional no jornalismo sensacionalista mascara a violência de gênero que culmina no assassinato de mulheres (Cárcela, 2008). Socialmente se minimiza a magnitude da violência contra as mulheres através de uma série de justificativas que não levam a suas causas estruturais, encarcerando-a na marginalidade como problema de "alguns", classificados como "loucos, anormais ou psicopatas". Essa estratégia discursiva sobre o agressor afasta o problema social de sua verdadeira causa (Martynowskyj, 2015).

Nesse universo do corpus, além do próprio "machismo", outro termo identificado foi "masculinidade tóxica". Trata-se de uma definição acerca da masculinidade que designa como ideal cultural características de violência e agressividade, além da repressão das emoções. Segundo Elisabeth Badinter (1993: 117), tradicionalmente a masculinidade se define mais por evitar determinados comportamentos do que propriamente desejá-los. "Ser homem significa não ser feminino; não ser homossexual, não ser dócil, dependente ou submisso, não ser afeminado na aparência física ou nos gestos [...]". A problematização da virilidade masculina como construção cultural e o posicionamento de suas expressões como negativas dão forma à "masculinidade tóxica".

Ademais, outros vocábulos como "macho" e "misógino" foram utilizados em títulos e subtítulos do corpus, referindo-se ao presidente da República Jair Bolsonaro ao defender o fim do isolamento social porque, segundo ele, "tem mulher apanhando em casa". A afirmação relaciona a suposta violência doméstica à fome e ao desemprego e não ao machismo, busca servir de justificativa para o fim do isolamento social, como defende abertamente Bolsonaro. Ao fazer esse tipo de comentário, o presidente, como líder nacional oculta a violência de gênero como problema estrutural e afirma que o lugar dos homens não é o espaço doméstico. Nas palavras de Francisco Ortega e Michael Orsini (2020: 1258, tradução livre), a resposta do governo Bolsonaro à crise sanitária tem sido "uma mistura virulenta de desconfiança populista da ciência, preconceito e masculinidade tóxica, transformada em um fervor nacionalista", o que se torna mais um entrave na luta pela igualdade de gênero.

De fato, a relação entre a violência doméstica e as causas questionáveis - como o desemprego, a fome e o consumo de álcool - esteve presente em uma pequena parte do conteúdo analisado. É importante situar que nenhum desses fatores são em si as reais condições que produzem violências contra mulheres, do contrário, ambientes antagônicos a estes seriam o horizonte para a superação dessas situa- 
ções, o que de longe não se configura como realidade. No entanto, é pertinente considerar que, através desses conteúdos - vulnerabilidade econômica e emocional -, manifesta-se uma das faces da violência de gênero que se relaciona com as condições de vida das mulheres. Nesse sentido, Mariane Pisani (2020) identificou em sua pesquisa que, no período da pandemia e em escala global, o álcool e as dificuldades financeiras - que surgem a partir da impossibilidade de trabalhar - foram o gatilho para comportamentos coercitivos, controladores e violentos por parte dos agressores.

Sobre a crítica mencionada contra Bolsonaro, outros políticos e instituições se somaram à lista, abarcando quase $10 \%$ da segunda parte do corpus. Em todos os casos foram discursos associados ao machismo os desencadeadores das críticas.

\section{Intersecções que complexificam as relações de gênero}

Ainda que o centro do debate seja a constatação de uma cultura que naturaliza o modelo de dominação/exploração nas relações de gênero, a forma como se materializam as desigualdades está determinada por outros marcadores sociais da diferença. O conceito de interseccionalidade, formulado pela feminista afro-americana Kimberlé Crenshaw (2002) há cerca de 30 anos, popularizou-se no Brasil recentemente, "sendo atualmente o conceito mais utilizado para analisar as relações e interconexões possíveis entre as categorias de gênero, raça, classe, sexualidade, geração etc." (Figueiredo, 2020: 12).

Assim, chama-nos atenção que em apenas 2,4\% do material de destacabilidade apareçam menções a marcadores sociais de classe, raça e etnia. Nas poucas vezes que essas interseccionalidades se fizeram presentes no conteúdo analisado, ou apontavam o racismo como problema social associado ao machismo, ou mencionavam grupos de maior vulnerabilidade durante a pandemia, como as pessoas residentes nas periferias e favelas e as trabalhadoras informais. Em um caso específico a preocupação com mulheres indígenas também apareceu.

A quase ausência de títulos e subtítulos com essa abordagem encontra paralelo ao modo como a própria imprensa feminista se constrói no Brasil e que, se não vem a pautar a imprensa nacional, ao menos a influencia no que concerne ao debate de gênero. No estudo desenvolvido por Elizabeth Cardoso (2004), ao analisar o conjunto de jornais feministas brasileiros a partir de sua concepção até o final da década de 1990, não houve menção a aspectos de raça, etnia e classe. Vale ressaltar que, ainda em meados da década de 1980, as ativistas feministas negras iniciaram 
"uma trajetória própria de autodeterminação política" (Nepomuceno, 2013: 400), formando diversas organizações feministas negras no país.

Ao analisar outros dados, de acordo com o Mapa da violência de gênero (Lutterbach, 2018), em 2017, as mulheres negras foram a maioria entre as que tiveram suas vidas ceifadas (64\% do total). E mais, segundo dados da Pnad Contínua (IBGE, 2019), o trabalho informal bateu recordes em 2019. Nesse grupo, as mulheres são maioria e somente na categoria de empregadas domésticas, acima de $70 \%$ estão na informalidade. São mais de seis milhões de profissionais atuando como domésticas, dessas, quase quatro milhões são negras, nas palavras de Angela Figueiredo (2020: 13), uma categoria "racializada e inferiorizada". Essas mulheres estão sujeitas a uma série de violências, para além do racismo, como assédio moral e sexual, estigmatização e baixos salários, que se agravam com a crise sanitária da Covid-19 (Pinheiro et al., 2020). Assim, os dados descortinam a ponta do iceberg resultante do enlace entre o machismo e o racismo.

Ora, na medida em que existe uma divisão racial e sexual de trabalho, não é difícil concluir sobre o processo de tríplice discriminação sofrida pela mulher negra (enquanto raça, sexo e classe), assim como seu lugar na força de trabalho (Gonzales, 2018:42).

Especificamente no contexto da pandemia, por meio de entrevistas com assistentes sociais e psicólogas, Bruna Tchalekian e Vera Paiva (2020: 13) concluem que "a crise da Covid-19 amplia as desigualdades que produzem a violência doméstica no cotidiano, intensificando a sinergia de violências produzidas pela vulnerabilidade social".

Nas redes, de forma mais evidente na última década, mulheres negras passaram a garantir o debate de pautas específicas do feminismo negro, enfocando também relações de classe, e contribuindo para dar voz a essas mulheres (Weschenfelder \& Fabris, 2019). Para Figueiredo (2020: 4), "essas mudanças formaram o amálgama necessário para eclodir um movimento de mulheres negras, plural e diverso". Se as consequências do machismo e do racismo associados são problematizados nesses ambientes de militância na internet, ele parece ainda não ocupar outras arenas, como apontam os resultados apresentados por este estudo.

Para a mulher indígena, incluída em apenas um dos títulos ou subtítulos analisados, a violência consequente do machismo é determinada pelas condições sociais em que estão inseridas, tanto em nível micro - referente à própria realidade - quanto no macro - concernente à sociedade envolvente, expondo-a ao racismo e ao colonialismo (Dutra \& Mayorga, 2019). 
2. Ao citarmos a ideia de casa-grande como lugar em que se produz o poder patriarcal no Brasil, fazemos referência a um debate clássico do pensamento social brasileiro. É na obra de Gilberto Freyre, no livro CasaGrande \& Senzala: formação da família brasileira sob o regime de economia patriarcal publicado pela primeira vez em 1930, que se constrói no país uma das primeiras análises sobre as raízes da nossa formação social, destacando a ideia de família e casa como símbolo da dominação patriarcal. Ainda que seja uma obra passível de inúmeras críticas, principalmente no que toca ao olhar do autor sobre as mulheres, o estudo revela de modo profundo as disposições dos diferentes grupos de mulheres (negras, indígenas e brancas) como premissa para a instalação do sistema econômico colonial.
Por fim, ainda que não tenha aparecido na discussão dos resultados como assunto específico, a presença de palavras-chave que apontam para a constatação da casa como lugar inseguro merece reflexão. Essa questão transita em outros tópicos anteriormente discutidos e se associa à própria lógica do confinamento e/ou isolamento social, quando relacionada à violência nos títulos e subtítulos. De forma ainda mais explícita, identificamos 11 ocorrências que verbalizam a casa ou o lar como ambiente de insegurança para mulheres e 87 ocorrências de verbos que indicam "risco" ou "alerta".

Como vimos, este é o ambiente em que se vive de modo mais enfático as violências nas relações de gênero. Ao blindar com a ideia culturalmente construída de que o mundo privado não deve ser posto em praça pública, encontramos exatamente na estrutura deste universo as condições para a perpetuação de situações de violência, tanto pela possibilidade do ocultamento, quanto da manutenção constante do medo ou do isolamento, que se intensificam no contexto ora estudado. Como bem afirma Bandeira (2014: 450), a violência de gênero "começa no universo familiar, onde as relações de gênero se constituem no protótipo de relações hierárquicas".

Aqui nos interessa sugerir que a formação do patriarcado, especialmente no Brasil, tem a casa como seu berço. É sob o teto da casa-grande², no interior das famílias, que os senhores patriarcais exercitam livremente o poder que Ihes é conferido (Freyre,1954). São nessas relações que aprendem a dominar e a expandir os seus domínios, destinando, sobretudo às mulheres, o lugar da subalternização. Se a casa como ambiente inseguro se torna o centro de gravidade evocado pela atual crise política e sanitária, é exatamente pelo fato de que não se pode escapar desse lugar para entender e complexificar as violências nas relações de gênero.

\section{Conclusões}

Retomamos aqui a questão que move esta pesquisa, a saber: como os conteúdos sobre machismo e violência de gênero no contexto da pandemia de Covid-19 se apresentam em sites brasileiros no primeiro momento da crise sanitária? No corpus analisado, observamos uma prevalência de conteúdo jornalístico e de instituições governamentais. Acerca do conteúdo jornalístico, responsável por $72 \%$ dos materiais, verificamos um equilíbrio entre fontes regionais e nacionais/internacionais, o que aponta, por um lado, para uma universalização da pauta e, por outro, para a presença do tema fora da grande imprensa. Se há coincidências ou divergências no tratamento dado à temática nos dois segmentos é uma questão a ser verificada em estudo posterior. Uma suposta neutralidade referente ao posicionamento ideológico da fonte foi maioria, seguida daquelas que se autodeclaram de esquerda e 
feminista. Tal resultado é esperado, como argumentamos, pelos fatos de que o conteúdo jornalístico prevaleceu na coleta, e de que raramente um veículo de imprensa autodeclara sua posição ideológica. Um estudo que utilize diretrizes mais sutis para classificar fontes ideologicamente pode render resultados mais nuançados.

No que diz respeito à natureza dos conteúdos publicados, destacamos a predominância de textos que não discutem as razões mais profundas e estruturais da violência de gênero, ou que atribuem o problema ao machismo e a todas as desigualdades dele decorrentes. Quantitativamente, prevalecem materiais que:

i. destacam uma fonte oficial ou personalidade como porta-voz do tema;

ii. divulgam ações correntes de combate à violência; e

iii. informam canais e formas de denúncia.

Sem deixar de reconhecer a importância social destas publicações, o cenário observado aponta para a necessidade de ampliar uma discussão que ultrapasse a superfície do problema e trate objetivamente de sua causa, bem como implique o Estado e a sociedade em suas possíveis soluções.

Os dados quantitativos provenientes das análises, para além de seu significado, foram propulsores de um debate social urgente. Verificamos que a violência doméstica foi central no conteúdo analisado, como bem afirmamos. Nesse sentido, embora tenhamos constatado a carência de uma problematização que trouxesse à luz as causas estruturais que levam às desigualdades e a sua face mais cruel, marcada pelo medo e pelo controle, também entendemos que a visibilidade que o problema recebeu, em alguma medida, se configura pelo fortalecimento de um debate que, cada vez mais, não se contenta em estar isolado em locais específicos.

Uma variedade de personalidades e entidades verbalizou os riscos que mulheres do todo o mundo sofrem ao se confinarem com seus agressores, como medida que garante a segurança sanitária e, contraditoriamente, agudiza a insegurança física e psicológica para uma parcela importante da população feminina. Nesse sentido, os resultados apontam para um silenciamento de representações dos inúmeros movimentos de mulheres e outras organizações especializadas em desigualdades de gênero que atuam no país para defender os direitos e a integridade das mulheres. Assim, aquelas que foram ouvidas, bem como o papa Francisco e o secretário-geral da OMS, enfatizaram que a violência contra a mulher se configura um problema global. 
É certo que a universalização das desigualdades de gênero não consegue abarcar as diferenças marcadas por intersecções alicerçadas em raça/etnia e classe, por exemplo, e que esses nós revelam especificidades da dominação/exploração de mulheres. Assim, a geopolitização do debate feminista é prerrogativa para uma construção de conhecimento concernente à materialidade das múltiplas vivências. A omissão dessa discussão nos textos analisados também nos parece sintomático de uma sociedade machista, classista e racista, como a brasileira. Ainda assim, entendemos que a confluência entre as variadas realidades se caracteriza pela violência que em tantas regiões e países do mundo se acentua - ou se revela com maior evidência - em tempos de isolamento social.

Outras expressões da desigualdade de gênero se apresentam em nossos achados. Nesse sentido, ganharam evidência a sobrecarga de trabalho doméstico e o cuidado com os filhos, bem como o fato de as profissionais da saúde que se posicionam na linha de frente para o combate ao vírus serem mulheres. Nesse jogo desigual, atua o ideal de reciprocidade que naturaliza o cuidado do outro como função social das mulheres. A crise sanitária colocou em evidência o que o feminismo há tempo considera fundamental: a interdependência entre as esferas produtiva e reprodutiva, cuja invisibilidade se configura um dos pontos mais problemáticos de nossa sociedade capitalista.

Potencialmente, essa crise deixa como lição - ou possível legado - um olhar para a invisibilidade que historicamente desvaloriza o trabalho do cuidado. O chamado home office e a presença ininterrupta de crianças no espaço do lar, ao menos para uma parcela da população, materializou as conexões entre as duas esferas, escancarando que a economia considerada produtiva se sustenta no trabalho do cuidado. Como proposição, inspiradas por Karina Batthyáni (2020), secretária executiva

3. O Clacso criou o Observatório Social do Coronavírus, com acesso aberto às contribuições de inúmeros pesquisadores que, a partir de uma diversidade de países, enfoques e campos do conhecimento, abordam - através de textos breves uma leitura sobre os efeitos sociais da pandemia. do Conselho Latino-Americano de Ciências Sociais (Clacso) ${ }^{3}$, a pandemia clama que é o momento de começar a pensar em novas formas de organização social em que o cuidado seja protagonista e as instituições sejam universais, públicas e gratuitas em prol do coletivo. "Recuperar a dimensão política da vida cotidiana parece ser um caminho a transitar" (Batthyáni, 2020: 4, tradução livre). Trata-se, no caso brasileiro, de um desafio que tem o cenário político como complicador. A crise democrática, que é uma crise dos direitos humanos, torna o ambiente social menos permeável a esta discussão. Os ataques contra os direitos das mulheres, duramente conquistados, devem ser desvelados e ocupar o centro do debate público. Como afirma Joana Maria Pedro (França, Priori \& Galinkin, 2020), precisamos muito do feminismo para a garantia de direitos já estabelecidos em um cenário de tantos retrocessos. 
Por fim, quando nos perguntamos acerca de outros desdobramentos desse período excepcional em escala mundial, e mais especificamente no Brasil, somos desafiadas a vislumbrar um momento posterior, pós-pandêmico. Desde a formação colonial do Brasil, o esquema político e econômico que se ergue apresenta a família como sua base. E a casa é justamente este local que historicamente não é apenas inseguro para as mulheres, mas que se organiza como estrutura que produz a insegurança. Como determinar essa mesma casa como espaço ideal para o confinamento tão necessário no combate ao vírus que provoca a atual pandemia? Esse é provavelmente o maior paradoxo que a pandemia impõe quando direcionamos nosso olhar às violências de gênero. Sem a inclusão das experiências das mulheres em todos os debates que busquem soluções para as problemáticas do mundo social, pouco se pode avançar.

\section{Referências}

AGUIAR, Sonia. Territórios do jornalismo: geografias da mídia local e regional no Brasil. Rio de Janeiro: Vozes; Editora PUC-Rio, 2016.

ARAÚJO, Anna Bárbara. Gênero, reciprocidade e mercado no cuidado de idosos. Revista Estudos Feministas, v. 1, n. 27, p. 1-13, 2018.

BADINTER, Elisabeth. XY: sobre a identidade masculina. Rio de Janeiro: Nova Fronteira, 1993.

BALLESTRIN, Luciana. Feminismos subalternos. Revista Estudos Feministas, v. 25, n. 3, p. 1035-1054, 2017.

BANDEIRA, Lourdes Maria. Violência de gênero: a construção de um campo teórico e de investigação. Revista Sociedade e Estado, v. 29, n. 2, p. 449-469, 2014.

BARDIN, Laurence. Análise de conteúdo. Lisboa: Edições 70, 2009.

BATTHYÁNI, Karina. La pandemia evidencia y potencia la crisis de los cuidados. Observatorio social del Coronavírus, Colección "Pensar la Pandemia-on-line", p. 1-4, Buenos Aires, Consejo Latinoamericano de Ciencias Sociales (Clacso), 2020.

BOBBIO, Norberto. Direita e esquerda. Razões e significados de uma distinção política. São Paulo: Editora Universidade Estadual Paulista, 1995.

CÁRCELA, Rosa. Del crimen pasional a la violencia de género: evolución y su tratamiento periodístico. Ámbitos, v. 11, n. 17, p. 171-188, 2008. 
CARDOSO, Elizabeth. Imprensa feminista brasileira pós 1974. Revista Estudos Feministas, v. 12, n. 264, p. 37-55, 2004.

CARRASCO, Cristina. A sustentabilidade da vida humana: um assunto de mulheres? In: NOBRE, M.; FARIA, N. (Orgs.). A produção do viver: ensaios de economia feminista, p. 11-49. São Paulo: Editora Sempreviva Organização Feminista, 2003.

CONSELHO FEDERAL DE ENFERMAGEM (COFEN). A luta contra o Coronavírus tem rosto de mulheres, 2020. Disponível em: <http://www.cofen.gov.br/a-luta-contra-o-coronavirus-tem-o-rosto-de-mulheres_79476.html>. Acesso em: 12 Maio 2020.

CRENSHAW, Kimberlé. Documento para o encontro de especialistas em aspectos da discriminação racial relativos ao gênero. Revista Estudos Feministas, v. 10, n. 1, p. 171-189, 2002.

DUTRA, Juliana; MAYORGA, Claudia. Mulheres indígenas em movimento: possíveis articulações entre gênero e política. Psicologia: Ciência e Profissão, v. 39, p. 113129, 2019.

FIGUEIREDO, Angela. Epistemologia insubmissa feminista negra decolonial. Tempo e Argumento, v. 12, n. 29, p. 1-24, 2020.

FRANÇA, Fabiane; PRIORI, Claudia; GALINKIN, Ana Lúcia. Os impactos da pandemia (Covid-19) no cotidiano das pessoas: desafios e contribuições dos estudos de gênero e dos feminismos - Entrevista com Joana Maria Pedro. Revista Educação e Linguagens, v. 9, n. 17, p. 11-25, 2020.

FRASER, Nancy. Unruly Practices: power, discourse and gender in contemporary social theory. Minneapolis, MN: University of Minnesota Press, 1989.

FREYRE, Gilberto. Casa-Grande \& Senzala: formação da família brasileira sob o regime de economia patriarcal. São Paulo: José Olympio, 1954.

GONZALEZ, Lélia. Primavera para as rosas negras: Lélia Gonzalez em primeira pessoa. São Paulo: Editora Filhos da África, 2018.

HIRATA, Helena; KERGOAT, Danièle. Novas configurações da divisão sexual do trabaIho. Cadernos de Pesquisa, v. 132, n. 37, p. 595-609, 2007.

HOLHFELDT, Antonio. Objectivity: a mythicized journalistic category. Revista Famecos, v. 11, n. 24, p. 31-40, 2008. 
INSTITUTO BRASILEIRO DE GEOGRAFIA E ESTATISTICA (IBGE). Pesquisa Nacional por Amostra de Domicílios Contínua (Pnad Contínua), 2019. Disponível em: <https://agenciadenoticias.ibge.gov.br/agencia-noticias/2012-agencia-de-noticias/ noticias/25534-desemprego-cai-para-11-8-com-informalidade-atingindo-maior-nivel-da-serie-historica>. Acesso em: 17 Maio 2020.

. Pesquisa Nacional por Amostra de Domicílios Contínua (Pnad Contínua). Disponível em: <https://sidra.ibge.gov.br/tabela/6373>. Acesso em: 16 Maio 2020.

INSFRAN, Fernanda; MUNIZ, Ana. Maternagem e Covid-19: desigualdade de gênero sendo reafirmada na pandemia. Diversitates International Journal, v. 12, n. 2, p. 26-47, 2020.

LUTTERBACH, Maria. Mapa da violência de gênero. Gênero e número, 2018. Disponível em: <https://mapadaviolenciadegenero.com.br/>. Acesso: 15 Maio 2020.

MARANHÃO, Romero. A violência doméstica durante a quarentena da Covid-19: entre romances, feminicídios e prevenção. Brazilian Journal of Health Review, v. 3, n. 2, p. 3197-3211, 2020.

MARTINEZ, Monica et al. Estudos de gênero na pesquisa em jornalismo no Brasil: uma tênue relação. Revista Famecos, v. 23, n. 2, 2016.

MARTYNOWSKYJ, Estefania. Locos, psicópatas, anormales... o de las estrategias discursivas para invisibilizar el carácter estructural de la violencia de género. Temas y Debates, v. 5, n. 19, p. 161-174, 2015.

MBEMBE, Achille. Necropolítica. São Paulo: n-1 edições, 2018.

MONTEIRO, Solange et al. A produção acadêmica sobre a questão da violência contra a mulher na emergência da pandemia da Covid-19 em decorrência do isolamento social. Doxa: Revista Brasileira de Psicologia e Educação, v. 22, n. 1, p. 152-170, 2020.

NEPOMUCENO, Bebel. Mulheres negras: protagonismo ignorado. In: PINSKY, C. B.; PEDRO, J. M. (Orgs.), Nova história das mulheres no Brasil, p. 382-409. São Paulo: Contexto, 2013.

ORTEGA, Francisco; ORSINI, Michael. Governing Covid-19 without government in Brazil: ignorance, neoliberal authoritarianism, and the collapse of public health leadership. Global Public Health, v. 15, n. 9, p. 1257-1277, 2020. Disponível em: <https://doi.org/10.1080/17441692.2020.1795223>. Acesso em: 23 Ago. 2020. 
PATEMAN, Carole. Críticas feministas a la dicotomía público/privado. Buenos Aires: Paidós, 1996.

PESSOA, Brenna; NASCIMENTO, Elaine. Feminicídio e Covid-19: duas expressões da questão social. Revista Espaço Acadêmico, n. 224, p. 37-46, 2020.

PINHEIRO, Luana et al. Vulnerabilidade das trabalhadoras domésticas no contexto da pandemia de Covid-19 no Brasil. Brasília: ONU Mulheres; Ipea, 2020. Disponível em: <https://www.ipea.gov.br/portal/images/stories/PDFs/nota_tecnica/200609_ nt_disoc_n_75.pdf>. Acesso em: 20 Abr. 2020.

PISANI, Mariane. O enfrentamento e a sobrevivência ao Coronavírus também precisa ser uma questão feminista! Cadernos de Campo, v. 29, n. 1, p. 156-162, 2020.

ROCHA, Rose; SILVA, Josefina. Alteridade de gênero e deslocamentos de sentido como práticas feministas em rede: observações sobre a página "Moça, você é machista". Contracampo, v. 35, n. 2, p. 33-51, 2016.

RODRIGUES, Carla. A quarta onda do feminismo. Revista Cult, v. 25, n. 219, p. 3047, 2016.

SAFFIOTI, Heleieth. Gênero patriarcado violência. São Paulo: Expressão Popular, 2015.

TCHALEKIAN, Bruna; PAIVA, Vera. Violência contra a mulher: vulnerabilidade programática em tempos de SARS-COV-2/Covid-19 em São Paulo. Revista Psicologia \& Sociedade, n. 32, p. 01-20, 2020.

VALENTE, Jonas. Apresentação do dossiê temático "Algoritmos, economia e poder". Revista Eptic, v. 22, n. 2, p. 56-63, 2020.

VARGAS VALENTE, Virginia. Los feminismos latinoamericanos en su tránsito al nuevo milenio. Una lectura político-personal. In: MATO, D. (org.). Cultura, política y sociedad. Perspectivas latinoamericanas. Buenos Aires: Clacso, 2005.

WESCHENFELDER, Viviane; FABRIS, Elí. Tornar-se mulher negra: escrita de si em um espaço interseccional. Revista Estudos Feministas, v. 27, n. 3, p. 1-15, 2019. 